\title{
LOUIS DUMONT EM INTERLOCUÇÃO COM FILÓSOFOS*
}

\author{
Delcides Marques**
}

RESUMO: O presente artigo propõe uma busca prioritariamente focada em alguns dos elementos referidos ao modo como a interlocução com alguns filósofos se fez presente e foi fundamental para que Louis Dumont elaborasse determinados conceitos estratégicos para a sua reflexão: igualdade, hicrarquia $\mathbf{e}$ apercepção sociológica. Trataremos essencialmente destes conceitos centrais para uma de suas obras, Homo hierarchicus. Nesse sentido, veremos primeiramente uma breve apresentação da citada obra de Dumont. São abordados alguns dos dilemas encontrados $\mathrm{cm}$ diversos antropólogos $\mathrm{em}$ relação à filosofia. Propomos também o desafio de perceber as implicações da abordagem empreendida por Dumont a tal questão. Por fim, enunciaremos lampejos de sua teoria em trabalhos mais recentes.

PALAVRAS-CHAVE: teoria antropológica, filosofia, comparação, apercepção sociológica

\section{INTRODUÇÃO}

O que guia minha resposta ć uma preocupação em mostrar que o realismo burguês de senso comum, quando tomado como um conceito historiográfico, é um tipo de violência simbólica feita a outros tempos e a outros costumes. Quero

\footnotetext{
* Este artigo tem como precursor $\mathrm{e}$ inspirador um trabalho apresentado à disciplina "História $\mathrm{c}$ 'Tcoria da Antropologia II", ministrada pela l'rofa. Dr. Suely Kofes, durante o scgundo semestre de 2007. Devo muito ao vivo diálogo com $A$ dalton Marques, Daiane Marques, Eduardo Dullo c Gabricl Pugliese.

** Graduando em Fïlosofia pela Universidade de São Paulo (FFLCII-USP). Graduado em Sociologia e Política pela Fundação Escola de Sociologia c Política de São Paulo (FESP'-SP). Mestrando no Programa de l'ós-Graduação cm Antropologia Social, PPGAS-IFCH/UNICAMP.
} 
sugerir que não se pode fazer uma história de qualidade, nem mesmo história contemporânea, sem respeito às ideias, ações e ontologias que não são $\mathrm{c}$ nunca foram as nossas próprias. Diferentes culturas, diferentes racionalidades (Marshal Sahlins, 2001 [1995], p. 29).

Antes de qualquer coisa, é preciso dizer que não é sempre que um livro recebe tantas resenhas como o Homo hierarchicus de Louis Dumont. Desde seu lançamento a obra se tornou referência para diversas discussões antropológicas (e indológicas). Num breve levantamento bibliográfico realizado no site wvww.jstor.org sobre a repercussão de Homo hierarchicus, acham-se as resenhas elaboradas por autores citados por Dumont (McKim Marriott, Nur Yalman, Gerald Berreman e Stanley J. Tambiah) e por autores que, mesmo não citados, entram no debate com cle: C. J. Fuller, R. S. Khare, Michael M. Ames, Paul G. Hiebert, Pauline Kolenda, Joseph E. Schwartzberg, N. J. Allen, Brian K. Smith e Steve Barnett. A obra de Dumont é ainda uma retomada teórica de indólogos como M. S. Srinivas, A. C. Mayer, D. F. Pocock, L. S. O’Malley, J. H. Hutton, C. Bouglé, E. A. Blunt e F. G. Bailey.

O próprio Dumont faz um balanço acerca das influências, debates e repercussões num prefácio escrito doze anos após a publicação da obra em francês e oito anos após a sua tradução inglesa (Dumont, 1992 [1966], p. 11-40). Neste prefácio, Dumont retoma a complexa e algumas vezes contraditória acolhida de Homo hierarchicus nos estudos indológicos. Nas palavras de Dumont, os críticos acabariam, por sua vez, mesclando "a aprovação e a censura" (idem: 12). No sentido da censura, uma das resistências à obra vinculou-se $\mathrm{e}$ foi "reforçada pela aversão à hierarquia, que é geral entre nossos contemporâneos e entre os modernos". Dumont ainda ressalta que poucas vezes o livro teria sido tratado como o que pretendeu ser: "uma espécie de experiência" (ibidem: 16) que busca o empirismo em detrimento do empiricismo (ibidem: 17-18).

Duas outras indicações precisam ser feitas, apesar de não levadas adiante. No caso brasileiro, já em fins dos anos da década de 1970, Roberto DaMatta (1997 [1978], p. 20s; 158s) articulava o pensamento de Dumont à sua investigação do dilema brasileiro por meio das noções de individualismo e

Temáticas, Campinas, 16(31/32): 291-313, jan./jun. 2008 
hierarquia. Nos Estados Unidos dos últimos anos de 1980, Arjun Appadurai (1988), por sua vez e em outro sentido, propôs uma revisão da presença e influência de Homo hierarchicus no meio acadêmico, principalmente como conceito (segundo ele, hegemônico) de hierarquia. Apesar de não nos atermos às duas abordagens, fica a indicação.

Antes de continuarmos, cabem alguns apontamentos das relações entre essa c outras obras de Dumont. Diversos temas abarcados na citada obra podem ser vistos como retorno a trabalhos anteriores ou como antecipação de discussões que seriam aprimoradas em trabalhos posteriores. Como uma ilustração de retorno a um trabalho precedente, há a retomada da comparabilidade entre a sociedade indiana e a "nossa" (sociedade moderna), da origem da moderna concepção de indivíduo e da organização social e do parentesco indiano (cf. Dumont, 1957; 1989 [1964]; 1965). Ilustrações de temas antecipados em Homo hicrarchicus referem-se às gêneses da ideologia econômica e individualista. No primeiro caso, da moderna ideologia econômica, Dumont recorre direta e constantemente a Marx (Dumont, 2000 [1977]) e ao discutir a moderna idcologia individualista ele se utiliza da tradição francesa de sociologia (Dumont, 1985 [1983]). Tal distinção não é radical e abrupta, pois Marx permanece presente na obra posterior e a escola francesa se encontrava também no trabalho de 1977. Em suma, as obras de Dumont se completam e se alternam.

Com relação ao conceito de ideologia, é preciso ainda esclarecer que Dumont não o toma em seu habitual sentido negativo. De modo simples, ele designa um conjunto mas ou menos social de idéias, crenças e valores (cf. Dumont, 2000 [1977], p. 19). É assim que ele pôde, anteriormente, contrapor a ideologia moderna do igualitarismo com a ideologia hierárquica do sistema de castas.

Uma vez diagnosticado um dos problemas implicados em boa parte das recepções críticas recebidas, entrevisto o que o livro teve como pretensão fundamental e mencionada a sua relação com outras obras de Dumont, resta dizer o que pretendemos aqui. Após vermos aspectos das relações entre antropologia e filosofia, faremos algumas incursões em temas gerais que julgamos perpassar a obra e recobrir dimensões teóricas e metodológicas fundamentais. Destacaremos o modo como Dumont lidou com filósofos e com temáticas filosóficas (na relação que podem estabelecer com a

Temáticas, Campinas, 16(31/32): 291-313, jan./jun. 2008 
antropologia), seguiremos a inspiração teórica para a elaboração do conceito de "apercepção sociológica" c vercmos como o método comparativo dumontiano pode ser (rc)lido a partir de (outros) autores recentes.

\section{FILÓSOFOS E FILOSOFIA: REJEITADOS AQUI, RECUPERADOS ALI}

[...] os devaneios filosóficos aos quais cedi de tempos em tempos têm um lugar bem modesto em meus escritos (Claude Lévi-Strauss, 1998, p. 109).

Não pretendo realizar uma revista dos embates entre antropologia e filosofia. Não pretendo porque não possuo a habilidade necessária. Mas me interesso, todavia, pelo levantamento de alguns pontos que me chamam a atenção sobre as relações entre os produtores de ambos os saberes. Na verdade, priorizando o modo como antropólogos lidaram com filósofos. Às vezes parece-me que os antropólogos tiveram mais dificuldade de lidar com a filosofia do que com certos filósofos. E isso se afigurou ainda mais explícita e perceptivelmente $\mathrm{cm}$ tempos $\mathrm{em}$ que a antropologia-sociologia procurava seu lugar entre as ciências ou em tempos de ameaça de indistinção entre os saberes. Vejamos breves exemplos de tais impressões.

Émile Durkheim rejeita e incorpora as incessantes discussões entre racionalistas e cmpiristas ao apresentar o fundamento social e sociológico das categorias do entendimento: tempo e espaço. Em seu caso, há uma interpenetração entre sociologia da religião e teoria do conhecimento (Durkheim, 1989 [1912], p. 38). Ainda próximo de temáticas kantianas, Durkheim incorporou o problema moral às questões sociológicas. Para ele, $\mathrm{em}$ suma, Immanuel Kant teria apontado um aspecto fundamental, mas não o único, para uma investigação do fato moral. O imperativo categórico kantiano isolado seria apenas um aspecto abstrato da realidade moral. Nesse sentido, além do dever (obrigação), o fim moral também deveria ser desejado e desejável (bem) (Durkheim, s/d [1906]). Vemos com isso uma afirmação da sociologia, mas em termos e com temas considerados propriamente filosóficos, que servem de motivo de crítica e de inspiração. 
No caso do sobrinho de Durkheim, Marcel Mauss, há uma crítica direta aos filósofos, mas principalmente à filosofia. Ele aproxima os filósofos dos teólogos ao acusá-los de ctnocêntricos. Ainda que tenham deixado suas contribuições, filósofos e teólogos teriam investigado não os fenômenos sociais, mas as idéias que faziam deles. Num conhecido texto de parceria, Durkheim e Mauss (1999 [1903], p. 400) afirmaram que as categorias lógicas de classificação deveriam ser analisadas como procedentes de representações coletivas. Em mais uma de suas parcerias, desta vez com Paul Fauconnet, a crítica de Mauss incidiu sobre um pensamento metafísico que abstrairia o homem como um ser à parte da natureza. Nesse sentido, houve a indicação de que a filosofia deveria se harmonizar com a ciência a partir de seus resultados, e não o contrário (Mauss \& Fauconnct, 1999 [1901]). Como decorrência disso, e num caminho de rejeição às elaborações de Lucien Lévy-Bruhl, Mauss (1979 [1923], p. 161) afirmou que uma "Antropologia completa poderia substituir a Filosofia" no que tange à história do espírito humano. Suas palavras parecem ser mais severas que as de Durkheim.

Com Lévi-Strauss, Lévy-Bruhl foi mais uma vez objeto de crítica. Uma das principais censuras esteve ligada à sua pretensão de aplicar categorias $\mathrm{c}$ procedimentos lógicos oriundos da filosofia ocidental sobre os "primitivos". Teria sido devido a tal pretensão etnocentricamente generalizante que LévyBruhl poderia ver em tais povos apenas um pensamento pré-lógico baseado na afetividade, confusão e participação (Lévi-Strauss, 1976 [1962], p. 305). Em palavras ainda mais graves, encontramos a menção de que seria menos suportável para Jean-Paul Sartre admitir que o "selvagem possua 'conhecimentos complexos' e seja capaz de análise e de demonstração" do "que a um Lévy-Bruhl" (idem, p. 286). Ainda nesse texto, Lévi-Strauss a firma uma superação da "falsa antinomia entre mentalidade lógica e mentalidade pré-lógica”. Na crítica de Lévi-Strauss a Sartre ć possível perceber, em suma, uma operação de distanciamento (em Sartre) e de aproximação ( $\mathrm{cm}$ LéviStrauss) entre razão dialética e razão analítica ou de assimilação (cm Sartre) e de distinção (em Lévi-Strauss) entre história e etnologia. Para Lévi-Strauss a filosofia de Sartre serviria mais como um ponto de partida que de chegada. 
É o caso de apresentarmos alguns desdobramentos recentes das divergências entre Lévi-Strauss e Sartre, mesmo que apenas no âmbito da referência. Tendo ocorrido nos anos de 1960, a discussão foi retomada a partir da segunda metade da década de 1990 . Um artigo de Cristian Delacampagne e Bernard Traimond (1995) incitou a rediscussão. Não muito depois, houve uma réplica de Lévi-Strauss (1998a). Mais recentemente apareceu uma tentativa de recapitulação crítica do debate entre a fenomenologia existencialista sartreana e a antropologia estrutural lévi-straussiana (Frédéric Keck, 2005). Além de Sartre, outros filósofos franceses tiveram um interesse pela antropologia, principalmente aquela relacionada a Lévi-Strauss. Maurice Merleau-Ponty (1975 [1960]) escreveu um texto tido como uma homenagem que teria tomado Lévi-Strauss como continuador e inovador do pensamento maussiano - apesar de Delacampagne \& Traimond (1995) sugerirem, mais recentemente, que tal texto seria uma crítica velada ao antropólogo. Gilles Deleuze e Félix Guattari $(1972 ; 1975 ; 1980)$ iniciaram desde o início dos anos de 1970 uma discussão filosófica acerca da etnologia, mas antes disso, o próprio Deleuze já havia tratado da antropologia estrutural (Deleuze, 1988 [1968]; 2006 [1969]; 1974 [1973]).

Ainda que tenhamos visto breves críticas de Durkheim, Mauss e Lévi-Strauss à filosofia (ou mesmo aos filósofos), as coisas nem sempre eram assim. Ficou explícito que Durkheim manteve-se próximo e influenciado pelo pensamento de Kant. Como vimos, Durkheim questionou as categorias kantianas, mas podemos agora mencionar que ele acabou reencontrando o filósofo e reconhecendo a pertinência de sua distinção entre razão especulativa e razão prática como dois aspectos diferentes de uma mesma faculdade (Durkheim, 1989 [1912], p. 524). Mauss, mais arredio que seu tio, talvez seja um caso particular. Eu diria que a filosofia e os filósofos foram mais radicalmente rejeitados em Mauss do que em Durkheim.

Exploremos um pouco o tipo de influência filosófica sofrida por Lévi-Strauss. No caso, Jean-Jacques Rousseau. A pesar de aparecer reiteradas vezes rejeitando a filosofia, Lévi-Strauss esteve em interlocução intensa com Rousseau. Algo exageradamente, inclusive, ele chegou a considerá-lo “o mais etnógrafo dos filósofos" (Lévi-Strauss, 1996 [1955], p. 369) ou o "fundador 
das ciências do homem" (Lévi-Strauss, 1987 [1962], p. 41). Na referência de Rousseau à piedade, Lévi-Strauss encontrou elementos para uma crítica à filosofia do sujeito $\mathrm{em}$ tradição cartesiana. $O$ antropólogo reconheceu possuir interesses comuns aos do filósofo. Em linhas gerais, a defesa da constituição da passagem da natureza à cultura $\mathrm{e}$ a busca pela união do sensível e do inteligivel, mesmo que por caminhos distintos: Rousseau com o primado do sentimento e Lévi-Strauss com o do intelecto (idem; Dumont, 2005 [1988], p. 237).

Antes do modo como Dumont lida com a filosofia, vejamos dois outros exemplos de aproximação recuperativa entre esses saberes.

Gabriel Tarde, que retomaremos pouco mais adiante, tratou a filosofia como aliada privilegiada para a elaboração dos conceitos de repetição/imitação (Tarde, 1993 [1890]) e de mônada (Tarde, 2007 [1895]). Vem do âmbito filosófico o pano de fundo teórico para a sua claboração antropológica. Os descendentes de Durkheim, críticos da filosofia, a chamavam de psicologia social. Não é à toa que Durkheim e Tarde são vistos como antípodas inconciliáveis e que uma crítica à hegemônica tradição sociológica do primeiro acabou se tornando a recuperação da sociologia infinitesimal do segundo (Pugliese, 2007, p. 56).

Pierre Clastres, tal como Lévi-Strauss, teve uma formação em filosofia antes de se tornar etnólogo. Em seu caso, todavia, menos inspirado em Rousseau do que em Etienne La Boćtic (c outros, tais como Friedrich Nietzsche e Martin Heidegger). Clastres tratou do domínio político da chefia e do papel que a linguagem possui (ou não) em contraste com o poder político do Estado $\mathrm{e}$ de sua implicação coercitiva. Já em seu primeiro artigo ele buscava apreender a filosofia política indigena de recusa do Estado (Clastres, 1978 [1962]). O etnólogo defendia, ainda, que era possível dar estatuto empírico à dedução lógica operada por La Boétie referida a uma ontologia social pré-mau encontro/ malencontro (Clastres, 1982 [1976]). Ainda sobre Clastres, o filósofo Bento Prado Júnior (1985 [1982], p. 252) tratou de defender que se em Lévi-Strauss houve uma ruptura radical com a filosofia, o mesmo não se poderia dizer dele: "a prática da análise estrutural não interrompeu o convívio, por exemplo, com a filosofia alemã”. É preciso dizer que o próprio Clastres não se definia como estruturalista. 


\section{DUMONT, OS FILÓSOFOS E A FILOSOFIA}

Os conceitos filosóficos individuais não são algo fortuito e que se desenvolve por si, mas crescem em relação e em parentesco um com o outro; embora surjam de modo aparentemente repentino e arbitrário na história do pensamento, não deixam de pertencer a um sistema, assim como os membros da fauna de uma região terrestre - tudo isso se confirma também pelo fato de os mais diversos filósofos preencherem repetidamente um certo esquema básico de filosofias possiveis (Friedrich Nictzsche, 1992 [1885], p. 25-26).

No caso do autor que mais nos interessa aqui, a filosofia tem um papel fundamental e ambíguo. Enquanto alguns filósofos se tornam criticáveis pela universalização de teorias que só valem para nossas sociedades, outros servem de inspiração teórica. Se os primeiros produzem ideologia moderna e são nuançados, os últimos produzem teoria (social) e são incorporados. No primeiro grupo encontram-se, por exemplo, as filosofias de Rousseau e Alexis de Tocqueville. No outro grupo, por sua vez, há as filosofias de Platão e Gottfried Leibniz. A presentaremos primeiramente a leitura que Dumont faz dos dois primciros filósofos, ao tratar de igualdade. Depois disso, avistaremos a sua abordagem ao conceito de hierarquia a partir de Platão (e Talcott Parsons). Por fim, acompanharemos a elaboração e alguns dos desdobramentos da noção de apercepção sociológica.

\section{a) Revisando o conceito de igualdade: Rousseau e Tocqueville}

O problema da igualdade em Rousseau e em Tocqueville é tratado por Dumont a fim de demonstrar "quão recente e tardio é o desenvolvimento da idéia de igualdade e de suas implicações", ou, em outros termos, Dumont pretende realizar "uma exegese da ideologia igualitária dos modernos" (Dumont, 1992 [1966], p. 44 e 60). Vejamos, portanto, como Dumont retoma os dois filósofos.

Na leitura dumontiana de Rousseau - com ênfase distinta da encontrada cm Lévi-Strauss -, a bastante consensual insurreição do filósofo contra a 
desigualdade é nuançada, pois "suas idéias são muito moderadas e, em grande parte, tradicionais". Comentando o pensamento rousseauniano, Dumont diz que, para aquele, a igualdade tem um valor positivo que se encontra no fato de que cla é, antes de qualquer coisa, "um ideal que o homem introduziu na vida política para compensar o fato inelutáuel da desigualdade" (Dumont, 1992 [1966], p. 60 - grifo meu). O que indica, no mínimo, a artificialidade da igualdade.

Segundo Dumont, Rousseau teria como seu "primeiro mérito" a distinção (mais do que a passagem via propriedade) entre desigualdade natural ou física (que seria praticamente irrelevante) e desigualdade moral e política (estabelecida via convenção, legislação e consentimento dos homens). $\mathrm{Na}$ argumentação do próprio Rousseau, bastava-lhe provar que o estado de desigualdade não era, "em absoluto, o estado original do homem". Seu esforço centrou-se, ademais, em "expor a origem e o progresso da desigualdade, o estabelecimento e o abuso das sociedades políticas". Em suma: "Conclui-se dessa exposição que, sendo quase mula a desigualdade no estado de natureza, deve sua força e seu desenvolvimento a nossas faculdades e aos progressos do espirito humano, tornando-se, afinal, estável e legitima graças ao estabelecimento da propriedade e das leis" (Rousseau, 1978 [1754/55], p. 282 - grifo meu; cf. Kawauche, 2007, p. 108). Desse modo, o caráter inelutável da desigualdade não procede do arbítrio divino, mas do humano (Kawauche, 2007, p. 103, nota 14).

Se há uma inevitabilidade da desigualdade, a igualdade efetiva só poderia consistir na proporção. A igualdade, portanto, própria do plano político, mantém seu valor quando combinada com a liberdade e quando constituída de proporcionalidade, ou seja, quando aplicada razoavelmente. A igualdade moral é tida como deslocadora dos desdobramentos possíveis da desigualdade natural.

No privilegiamento temático dado a Tocqueville, Dumont ressalta "as duas virtudes cardeais" que são postas em contraste a partir das democracias inglesa, americana e francesa: "A Inglaterra ć a liberdade sem quase nada de igualdade. A América herdou em grande medida a liberdade e desenvolveu a igualdade. A Revolução Francesa fez-se totalmente sob o signo da igualdade" (Dumont, 1992 [1966], p. 61). É possível dizer que o problema central para Tocqueville refere-se ao "que fazer para que o desenvolvimento da igualdade irrefreável não seja inibidor da liberdade, podendo por isso vir a destruí-la?" 
(Quirino, 1989: 152). Para ele, o individualismo é de origem democrática e o egoísmo é fruto de "uma amor exagerado e apaixonado de si mesmo" (Tocqueville, 1979 [1835], p. 285). A democracia, apesar de prezar pela igualdade e liberdade, torna-se ameaçada pelo próprio individualismo. Se a aristocracia fizera de "todos os cidadãos uma cadeia, que ia do camponês ao rei; a democracia rompe a corrente e deixa cada elo à parte" (idem, p. 286).

Centremo-nos um instante no problema da igualdade. Dumont acusa a mentalidade democrática moderna de reificar um ideal que confunde igualdade com identidade. Um desastre é preconizado: se já não há hierarquias sociais ou culturais, mas os homens são vistos como iguais e idênticos em essência, as diferenças de natureza e estatuto entre comunidades são reafirmadas como "procedente de caracteres somáticos, é o racismo" (Dumont, 1992 [1966], p. 64). Em tal sociedade, e mesmo em Tocqueville, hierarquia e desigualdade são vistos como o oposto de igualdade. Segundo Dumont, é nesse momento que há um distanciamento entre ele e Tocqueville. Qual é a alternativa escolhida por Dumont, portanto?

\section{b) Hierarquia não é desigualdade: Parsons e Platão}

Dumont denuncia que muitas vezes, mais efetivamente entre sociólogos e filósofos, a palavra hierarquia causa certa repugnância por ser associada à desigualdade, fundada numa "hierarquia de poder". Ele afirma ter encontrado na sociologia de Talcott Parsons o mérito de colocar "em plena luz a racionalidade universal da hicrarquia" (idem, p. 66). É preciso ressaltar que Dumont não lida com "estratificação social" (como faz Parsons), pois esta seria uma expressão muito condicionada por uma história de incompreensões ao ser associada à "hierarquia envergonhada ou não consciente, reprimida" (ibidem, p. 118). Diante de tais contrastes e especificidades, Dumont conclui que a hierarquia deve ser entendida como "princípio de gradação dos elementos de um conjunto em relação ao conjunto". De modo que é "a religião que fornece a visão do conjunto e que a gradação será, assim, de natureza religiosa” (ibidem, p. 118). A relação hierárquica fundamental, melhor dizendo, a oposição hicrárquica central é a "existente entre um todo (ou um conjunto) e um elemento desse todo". Há o "englobamento de um contrário". Nesse sentido, a 
hicrarquia é tanto bidimensional como um "escândalo lógico", pois "toda a relação de um elemento com o conjunto de que ele participa introduz a hierarquia e é logicamente inaceitável" (Dumont, 1985 [1983], p. 229 e 278).

Enfim, para Dumont (e para Parsons) a hierarquia implica que "adotar um valor é hierarquizar". Assim, hierarquia independeria de desigualdades naturais ou da repartição do poder. Na verdade, é indispensável à vida social que haja um certo consenso sobre os valores, bem como uma certa hierarquia tanto de idéias e das coisas como das pessoas. Se na maioria dos casos a hierarquia se identifica de alguma maneira com o poder, "o caso indiano nos ensinará que não há nisso nenhuma necessidade" (Dumont, 1992 [1966], p. 66).

Além de pensar a hierarquia como gradação religiosa, foi-lhe preciso mostrar como a hierarquia se relaciona com a distribuição de poder, mas sem fazer como a ciência política que costuma tratar o poder em primeiro plano (idem, p. 273; Dumont, 2000 [1977], p. 22). Em breves palavras, no sistema de castas há um "tipo puro de hierarquia, perfeitamente separado daquilo a que a hicrarquia está misturada na maior parte do tempo, a saber, o poder". E tal hierarquia tem a forma estrutural da oposição puro/impuro entre grupos, pessoas, ocupações (Dumont, 1992 [1966], p. 110 c 273). Assim, “o conjunto está fundado na coexistência necessária e hierarquizada de dois opostos" (idem, p. 94).

Como se evidenciou, ao tratar da necessidade da hierarquia, Dumont se afastou de Tocqueville, mas ficou com Platão. Sem desenvolver adequadamente sua constatação sobre a pólis platônica - o que também não tentaremos aqui -, ele diz: "Os filósofos têm em sua própria tradição um exemplo mais feliz, a República de Platão, mas eles parecem embaraçados com ela" (idem, p. 66). Desse modo, ao apresentar a conceituação de hierarquia como gradação, é a partir de Platão que Dumont o faz (ibidem, p. 118; Dumont, 1989 [1964], p. 19). Os graus platônicos relativos à alma, à natureza, ao conhecimento, à função social, às ciências, ao lugar social etc., possibilitam a harmonização seja do homem seja da pólis. De igual modo, a referência supra à proporção rousseauniana evoca algo do ideal de justiça distributiva de Platão. E ele arremata: talvez, mais do que falar em igualdade, caberia o termo equiidade (Dumont, 1992 [1966], p. 60).

Uma súmula do seu argumento pode ser reduzida à defesa de que "a hierarquia é uma necessidade universal" e que o inicial, aparente e extremado 
individualismo de Rousscau (mas também de Hobbes e Hegel) é, também e no fundo, uma busca "para forçar o indivíduo a se fazer ou a se reconhecer homem social” (idem, p. 299). A partir de Tocqueville, foi fortalecido o argumento de que além de ser recente a apreensão ocidental dos homens como indivíduos, essa mesma concepção é bastante limitada entre eles mesmos. Além disso, foi o modo moderno de negação da hierarquia que Dumont considerou como o principal obstáculo, não apenas à compreensão do sistema de castas, mas principalmente da possibilidade de ampliação deste conceito.

\section{c) Apercepção, entre a monadologia e a sociologia: Leibniz}

Aqui, o debate com a filosofia continua. E muito menos que crítica, há incorporação. É assim que a apercepção sociológica de Dumont remonta fundamentalmente a Leibniz è̀ sua monadologia. Contudo, cabe dizer que a monadologia leibniziana foi utilizada de modos distintos por Tarde e Dumont.

Os princípios do conhecimento formulados por Leibniz (1979 [1974]) levaram-no a uma concepção do mundo oposta à cartesiana. Enquanto Descartes formula uma concepção geométrica e mecânica dos corpos, Leibniz constrói uma concepção dinâmica. Nesse sentido, explica os seres não como máquinas que se movem, mas como forças vivas. A partir da noção de matéria como essencialmente atividade, ele chega à idéia de que o universo é composto por unidades de força, as mônadas, noção fundamental de sua metafísica (cf. Leibniz, 2004 [1686], p. 50). Essa noção, contudo, não se esgota na adição do atributo força ao conceito de matéria, formulado por Descartes. Leibniz chega também à noção de mônada mediante a experiência interior que cada indivíduo tem de si mesmo e que o revela como uma substância ao mesmo tempo una e indivisível.

Com Tarde, a lição (neo)monadológica fundamental para a elaboração de um "ponto de vista sociológico universal" (Tarde, 2007 [1895], p. 91) vincula-se ao fato de que o universal só pode ser conhecido por meio da mediação do infinitesimal, das nuanças, do infinitamente pequeno e elementar, do imperceptível (idem, p. 58; Pugliese, 2007, p. 53, 56-57; Vargas, 2007, p. 12). Se Tarde propõe uma nova monadologia, ou uma monadologia renovada, ele acaba por reter o princípio da continuidade (fundamento do cálculo 
infinitesimal) e dos indiscerníveis (da diferença imanente), ao mesmo tempo cm que abre mão dos princípios da clausura e da harmonia preestabelecida (em suma, da hipótese de Deus) em que Leibniz havia encerrado as mônadas. As mônadas teriam sido fechadas rápido demais por uma concepção de Deus (idem, p. 14).

As mônadas leibnizianas são partículas elementares, ou seja, substâncias simples de que os compostos são feitos. Elas são, assim, "diferenciadas (dotadas de qualidades que as singularizam umas com relação às outras) e diferenciantes (animadas por uma potência imanente de mudança contínua ou de diferenciação)" (ibidem, p. 12). Nas palavras de Tarde, "existir ć diferir", de modo que "a diferença é o alfa e o ômega do universo" (Tarde, 2007 [1895], p. 98).

Vejamos como Dumont chega a Leibniz. O universal não é contemplado apenas pela consideração das semelhanças na comparação, mas e muito mais por meio das características próprias a cada sociedade, e que são sempre diferentes. Uma particularidade do universal (Dumont, 1992 [1966], p. 52). E o relativismo é fundamental, pois, enquanto se tomar a ideologia igualitária moderna como universal do ponto de vista moral, político e social não se pode compreender a outra teoria, diretamente contradita à nossa, do sistema das castas. É a partir daí que se torna possivel comparar, por exemplo, uma ideologia moderna (França, Alemanha etc.) com uma ideologia tradicional (Índia e China) (Dumont, 2000 [1977], p. 20s).

Para Dumont, a sociologia é produto e parte integrante da sociedade moderna. Ademais, e como vimos anteriormente, a sociedade moderna tem a igualdade e liberdade como idéias fundamentais. Ela supõe a noção de indivíduo. E este, por sua vez, apresentaria a essência da humanidade ao mesmo tempo em que a humanidade é constituída de indivíduos (Dumont, 1992 [1966], p. 52). O indivíduo seria uma mônada e a sociedade uma coleção/ associação de mônadas. Da noção de indivíduo (ou de homem individual) distingue-se: "o sujeito empírico, amostra indivisível da espécie humana, tal como é encontrado em todas as sociedades" e "o ser moral, independente, autônomo e, assim (essencialmente) não social, tal como é encontrado, sobretudo, em nossa ideologia moderna do homem e da sociedade. A distinção é indispensável para a sociologia" (Dumont, 1985 [1983], p. 28 c 280; ver também, 1992 [1966], p. 57). 
Para clarear o sentido do termo apercepção apropriado por Dumont da ontologia leibniziana, vejamos as notas que caracterizam as mônadas, c são elas: a percepção, a apercepção, a apetição e a expressão. Pela percepção as mônadas representam as coisas do universo; cada uma de per si espelha o universo todo. $A$ apercepção é a capacidade que a mônada espiritual tem de auto-representar-se, isto é, de refletir; a mônada é consciência. A apetição consiste na tendência de cada mônada de fugir da dor e desejar o prazer, passando de uma percepção para outra. Finalmente, as mônadas, não tendo "janelas por onde qualquer coisa possa entrar ou sair" (Leibniz, 1979 [1714], p. 105), não recebem seus conhecimentos de fora, mas têm o poder interno de exprimir o resto do universo, a partir de si mesmas; a mônada é um ponto de vista.

Se a noção de sociedade moderna surge numa concepção de sociedade igualitária, as suas raízes estão em outro lugar: na "apercepção da natureza social do homem". Ao indivíduo absoluto e auto-suficiente a apercepção opõe o homem social. Aqui, cada homem é visto não mais como "encarnação particular da humanidade abstrata, mas como um ponto de emergência mais ou menos autônomo de uma humanidade coletiva particular, de uma sociedade" (Dumont, 1992 [1966], p. 53).

Nesse sentido, a apercepção sociológica é contra-intuitiva. No caso, a obviedade do individualismo é posta em questão pela abordagem do social. Com a apercepção chegamos a compreender que a percepção de nós mesmos como indivíduos não é inata, mas socialmente aprendida (nesse ponto Dumont se aproxima bastante de Durkheim). Apesar de poder originar-se espontaneamente, a apercepção é uma experiência paulatina de conscientização sociológica que serve de base para o contato ou a investigação de outras sociedades. Com ela, pode-se "apreender nos outros a modelagem pela sociedade de traços que não vemos, ou quando tomamos por 'pessoais' em nós". Muda-se o modo de nos situarmos em relação aos outros, de modo que deixamos de pensar num "eu c os outros" e passamos a nos ver como um deles (idem, p. 55). 


\section{COMPARANDO COMPARAÇÕES: DESDOBRAMENTOS}

Como compreender o outro sem sacrificá-lo à nossa lógica $\mathrm{c}$ sem sacrificá-la a cle? Assimilando muito depressa o real a nossas idéias ou, então, declarando-o impermeável, a sociologia falava como se pudesse sobrevoar seu objeto e o sociólogo era um observador absoluto. Faltava-lhe uma penetração paciente no objeto e a comunicação com ele (Maurice MerleauPonty, 1975 [1960], p. 384).

É da apercepção (sociológica) que Dumont chega à sociologia comparada. "Por oposição à sociedade moderna, as sociedades tradicionais, que ignoram a igualdade c a liberdade como valores", ou seja, que ignoram o indivíduo, acabam por possuir "no fundo uma idéia coletiva do homem, e nossa apercepção (residual) do homem social é a única ligação que nos une a elas, o único viés pelo qual podemos compreendê-las". Estamos, portanto, no "ponto de partida de uma sociologia comparativa" (ibidem, p. 56). E, no caso de Dumont, o interesse é menos pela Índia contemporânea e seu desenvolvimento econômico moderno pós-independência que por sua organização social tradicional, "de um ponto de vista teórico comparativo" (ibidem, p. 41).

Seu ponto de vista é inspirado na tradição sociológica francesa, mas sobretudo em Marcel Mauss, que "mais do que conceitos, nos ensinou um método" (ibidem, p. 42). E o método comparativo, de acordo com Mauss e Paul Fauconnet (1999 [1901], p. 17), demonstrou que, "desde logo a história comparada das religiões, dos dircitos e dos costumes revelou a existência de instituições incontestavelmente idênticas entre os mais diferentes povos". Os autores rejeitam absolutamente que a causa destas concordâncias seja a imitação (em oposição a Tarde) ou um acidente: "o espírito se recusa a considerar como fortuitas a regularidade e a semelhança".

O sistema de castas diante de "nosso sistema social" teria sido formado mais como uma anomalia do que como uma instituição (Dumont, 1992 [1966], p. 49), mas Dumont pretende mostrar que "a casta tem alguma coisa a nos ensinar". Em suma, cla nos ensina um princípio social fundamental, a hierarquia, cujo oposto foi apropriado "por nós, modernos", mas que nos possibilita 
compreender a natureza, os limites e as possibilidades do nosso igualitarismo moral e político (idem, p. 50).

Tal abordagem não visa, todavia, atacar os valores dẹ nossa sociedade, mas "trata-se apenas de uma tentativa de apreender intelectualmente outros valores”. Há um círculo a ser percorrido: indo de nós às castas e voltando das castas a nós. Tratar as castas em termos de nossa concepção de "estratificação social" seria uma forma de não sair da posição inicial e de ficarmos fechados em nós mesmos (em oposição à apercepção sociológica) (ibidem, p. 50; ver, além disso, Dumont, 2000 [1977], p. 24).

Uma concomitância das mais espantosas é constituída pela existência, dentro da própria sociedade das castas e ao lado do sistema das castas, de uma instituição que a contradiz: a renúncia. Um homem pode morrer para o mundo social, escapar à rede de estrita interdependência e se "tornar para si mesmo seu próprio fim como na teoria social do Ocidente, a ponto mesmo de ser quase cortado da vida social propriamente dita": é o renunciante, um "individuo-fora-do-mundo".

Para “o sociólogo, o renunciante está na sociedade", o que implica no fato de que ela também organiza suas relações para ele, contudo o renunciante é um homem que abandona seu papel social para assumir um papel ao mesmo tempo universal e pessoal; csse é o fato crucial, subjetivo e objetivo". Nesse sentido, e considerando agora o conjunto que engloba a sociedade e o renunciante, fica perceptível que estão equilibrados, o mundo de estrita interdependência, onde o indivíduo é ignorado, c o mundo de uma instituição que põe fim à interdependência e instaura o indivíduo. A renúncia contradiz e se relaciona com o sistema de castas. Não há uma oposição sólida (A e B), mas uma distribuição particular do indivíduo c do coletivo $(A+B)$ (Dumont, 1992 [1966], p. 244)

Além dos filósofos já mencionados, há uma forte presença hegeliana (na elaboração de seu conceito de diferença e hierarquia) que se soma a uma herança maussiana na busca por um holismo e uma totalidade ao falar $\mathrm{cm}$ "sistema de castas": as castas seriam as partes e o sistema seria o todo (idem, p. 93). Numa definição dada pelo próprio Dumont (1985 [1983], p. 279): "Designa-se como holismo uma ideologia que valoriza a totalidade social e negligencia ou subordina o indivíduo humano [...] Por extensão, uma sociologia

Temáticas, Campinas, 16(31/32): 291-313, jan./jun. 2008 
é holista se faz parte da sociedade global e não do suposto indivíduo dado independentemente". Ao holismo se opõe - oposição enquanto distinção intelectual e não como uma relação factual $-\mathrm{o}$ individualismo enquanto ideologia que valoriza o indivíduo e negligencia ou subordina a totalidade social. Segundo Dumont, na distinção holismo/individualismo o extremo individualismo supõe um indivíduo-no-mundo, uma intramundanidade. De outro modo, na distinção intramundano/extramundano o extremo extramundano [indivíduo-fora-do-mundo] não se opõe ao holismo do mesmo modo que o intramundano: "De fato, o individualismo extramundano opõe-se bierarquicamente ao holismo: superior à sociedade, deixa-a no lugar, enquanto que o individualismo intramundano nega ou destrói a sociedade holista e substitui-a (ou pretende fazê-lo)" (Dumont, 1992 [1966], p. 67, nota 30). No plano lógico, o contraste holismo/individualismo e hierarquia/igualdade implica que o holismo se relaciona com a hierarquia e o individualismo com a igualdade, todavia, nem sempre as implicações se dão no mesmo grau.

Aproximando-nos do fim deste artigo-trabalho, vejamos de modo quase impalpável dois autores mais recentes e de alguma forma afins a Dumont: Marilyn Strathern e Eduardo Viveiros de Castro.

As relações entre parte $\mathrm{e}$ todo são trabalhadas de um modo bastante particular nos melanésios de Strathern. Segundo a antropóloga, uma das idéias que precisam servir de ponto de partida para scu trabalho é a de "sociedade", uma vez que ela própria "como uma metáfora para organização, organiza muito da maneira pela qual os antropólogos pensam" (Strathern, 2006 [1988], p. 37). E mais do que "demonstrar a inaplicabilidade deste ou daquele conceito ocidental", a sua preocupação é, bastante além disso, compreensiva e deslocadora (idem, p. 38-39). Seu deslocamento essencial propõe que paremos de pensar que no centro das culturas exista uma antinomia entre a "sociedade" e o "indivíduo" (e é nesse momento que ela menciona trabalhos nos quais entraria o de Dumont): "A história da antropologia está repleta de advertências no sentido de que não devemos reificar o conceito de sociedade, de que o individual é um construto cultural e uma corporificação de relações sociais, e assim por diante" (ibidem, p. 39).

O procedimento comparativo como confronto às nossas categorias antropológicas e sociais é radicalizado pela antropóloga. Ela declarou que, 
por estar aberta ao feminismo, acabou "jogando as certezas antropológicas contra as incertezas feministas e vice-versa" (Strathern, 1999, p. 159). A sua obra magna é um livro cujo corpo é "uma exposição do que penso serem as práticas de conhecimento melanésias", e cujas "conclusões reconsideram, sob essa luz, questões estritamente feministas (de dominação masculina) e antropológicas (de comparação entre culturas)" (Strathern, 2006 [1988], p. 21). A antropóloga colocou, enfim, as teorias ocidentais de construtivismo e desconstrutivismo sob a perspectiva das concepções melanésias (Strathern, 1997 [1992]).

A comparação que ela propõe não visa descontextualizar "os construtos locais para trabalhar com construtos contextualizados analiticamente" e "não se trata de imaginar que seja possível substituir conceitos exógenos por correspondentes nativos; a tarefa é, antes, a de transmitir a complexidade dos conceitos nativos com referência ao contexto particular em que são produzidos". Assim Strathern pretende "mostrar a natureza dos construtos nativos através da exposição contextualizada dos construtos analíticos" (Strathern, 2006 [1988], p. 33).

Viveiros de Castro (2004, p. 4), em termos distintos dos de Dumont mas muito possivelmente também inspirado nele -, afirma que "fazer antropologia é comparar antropologias, nada mais - mas nada menos". É uma afirmação que retoma diretamente a proposta de Roy Wagner de que "todo mundo é um pouco antropólogo" (1981 [1975], p. 36), mas que ressoa uma continuação também de Dumont. Viveiros de Castro busca levar a citada constataçãoàs suas últimas conseqüências ao questionara usual vantagem cpistemológica que o antropólogo tem sobre o nativo (Viveiros de Castro, 2002,p. 114).

Mesmo nessa parte do artigo, que tivemos como intenção mostrar desdobramentos do trabalho comparativo de Dumont, encontramos autores que mantêm um diálogo com a filosofia. Mesmo que não tenhamos explorado essa dimensão de seus trabalhos, podemos também nesse ponto aproximá-los de Dumont. Nesse sentido, eles realizam uma interlocução com filósofos a partir das características do material etnográfico que analisam c das perguntas que o material lhes sugere. É assim que podemos pensar as proposições de Dumont acerca do material etnográfico indiano, bem como as de Strathern em relação ao material melanésio, ou mesmo as de Viveiros de

Temáticas, Campinas, 16(31/32): 291-313, jan./jun. 2008 
Castro em relação à etnografia amazônica. Com isso, algum conhecimento dos temas alçados como preocupação teórica em cada uma das regiões, tornase fundamental para a comprecnsão da interlocução com a filosofia e dos conceitos produzidos por tais autores.

\section{CONCLUINDO, COM DRUMMOND E COM DUMONT}

Para finalizar o nosso percurso, pode ser interessante retomarmos um poema de Carlos Drummond de Andrade sobre uma temática que esteve presente em algumas das últimas páginas deste trabalho diretamente referido a Dumont. O poeta, portanto:
A pobreza do eu a opulência do mundo
A opulência do eu a pobreza do mundo A pobreza de tudo a opulência de tudo A incerteza de tudo na certeza de nada.

Evidentemente que este trabalho não foi sobre Drummond, mas sobre Dumont. Apesar disso, mais do que uma cadência fonética comum aos dois nomes, parece-me que há certa semelhança entre o verso de um e a antropologia do outro. Nesse sentido, e como talvez nos seja possivel perceber ao fim do trabalho, o balanço de Drummond entre o eu e o mundo pode ser lido a partir dos dumontianos dilemas intramundano e extramundano, individualismo e holismo, indivíduo e sociedade, encontrados em Homo hierarchicus.

Estamos diante do método comparativo de Dumont em relação à apercepção poética de Drummond. Depois de balançarmos entre igualdade e hierarquia, indivíduo e sociedade, intramundano e extramundano, individualismo $\mathrm{c}$ holismo, a pobreza do eu c a opulência do mundo/a pobreza do mundo e a opulência do cu, a conclusão de Dumont, além dos contrastes, é a de que "hierarquia e igualdade estão necessariamente combinados, de uma 
forma ou de outra, em todo sistema social" (Dumont, 2000 [1977], p. 14-15). Pendulamos, também, entre a ideologia moderna e a ideologia tradicional, entre o Ocidente e a Índia. Sem esquecer a oscilação fundamental entre filosofia $\mathrm{e}$ antropologia. E tudo isso para concluir que Dumont não lidou com tais dicotomias de modo inflexível. Na verdade, ele percebeu matizes, cruzamentos, complementaridades. Com Dumont, fica bem mais interessante aproximarse das mais recentes teorias c perceber que há nelas a própria atualização (crítica e continuadora) de seu pensamento.

ABSTRACT: The article proposes a search priory focused in some elements referred to the way as the dialogue with some philosophers are present and are also fundamental for Louis Dumont to elaborate certain strategic concepts in his reflection such as equality, hierarchy and sociological apperception. We essentially deals with some central concepts in his work Homo bierarbicus. In that sense, firstly we briefly present the mentioned work of Dumont and, secondly, some of the dilemmas found in the work of several anthropologists concerning to philosophy. We also propose do challenge the implications of the approach undertaken by Dumont to philosophy. Finally, we mention the influence of his theory in more recent works.

KEYWORDS: anthropological theory, philosophy, comparison, sociological apperception

\section{REFERÊNCIAS BIBLIOGRÁFICAS}

APPADURAI, A. Putting hierarchy in its place. Cultural Antbropology, v. 3(1), feb., p. 36-49, 1988.

CLASTRES, P. Troca e poder: Filosofia da chefia indigena. In: $A$ sociedade contra o Estado: Pesquisas de Antropologia Politica. Rio de Janeiro: Francisco Alves, p. 21-35, 1978 [1962].

. Liberdade, mau encontro, inominável. In: LA BOÉTIE, E. Discurso da servidão voltuntária. São Paulo: Brasiliense, p. 109-123, 1982 [1976].

DAMATTA, R. Carnavais, malandros e heröis: para uma sociologia do dilema brasileira. $\sigma^{a}$ ed. Rio de Janeiro: Rocco, 1997 [1978].

DELACAMPAGNE, C. \& TRAIMOND, B. A polêmica Sartre/Lévi-Strauss revisitada: Nas raízes das ciências sociais de hoje. Les Temps Modernes, 596, nov./dez., 1997.

Temáticas, Campinas, 16(31/32): 291-313, jan./jun. 2008 
DELEUZE, G. \& GUATTARI, F. L'anti-Oedipe Paris: Minuit, 1972.

Psychoanalysis and Ethnology. Sub-Stance. University of Wisconsin Press, v. 14(11/12), p. 170-197, 1975. Mille plateanx. Paris: Minuit, 1980.

DELEUZE, G. Em que se pode reconhecer o estruturalismo? In: CHÂTELET, François [org.]. História da Filosofia (v. 8-O século XX). Rio de Janeiro: Zahar, p. 271-303, 1974 [1973].

- Diferença e repetição. Rio de Janeiro: Graal, 1988 [1968].

. Lógica do sentido. São Paulo: Perspectiva, $4^{\mathbf{a}}$ ed., 2006 [1969].

DUMONT, L. Hierarcly and marriage alliance in south Indian kinship. London: Royal Anthropological Institute (Occasional papers, $\left.n^{\circ} 23\right), 1957$.

. The modern conception of the individual: Notes on its Genesis. Contributions to Indian sociology, VIII, p. 13-61, 1965.

. O individualismo: Uma perspectiva antropológica da ideologia moderna. Rio de Janeiro: Rocco, 1985 [1983].

. La civilización indiay nosotros. Madrid: Alianza Editorial, 1989 [1964].

. Homo bierarcbicus O sistema de castas e stuas implicações. São Paulo: Ed. da USP, 1992 [1966].

. Homo aequalis: Gênese e plenitude da ideologia econômica. Bauru: EDUSC, 2000 [1977].

DURKHEIM, É. As formas elementares da vida religiosa: O sistema totêmico na Austrália. São Paulo: Paulus, $2^{2}$ ed., 1989 [1912].

. Determinação do fato moral In: Sociologia, pragmatismo e filosofia. Porto: Rés-Editora, p. 209-238, s/d [1906].

KAWAUCHE, T. T. A santidade do contrato e das leis: Um estudo sobre religião e política em Rousseau. São Paulo, 2007. Dissertação (Mestrado em Filosofia) - Faculdade de Filosofia, Letras e Ciências Humanas, Universidade de São Paulo.

LEIBNIZ, G. W. A monadologia. In: A monadologia e outros textos (Os Pensadores). Trad.: Marilena de Souza Chauí. São Paulo: Abril Cultural, p. $103-115,1979$ [1714].

Temáticas, Campinas, 16(31/32): 291-313, jan./jun. 2008 
. Discurso de metafisica. São Paulo: Ícone, 2004 [1686].

LÉVI-STRAUSS, C. História e razão dialética. In: O pensamento selvagem. São Paulo: Ed. Nacional, p. 280-306, 1976 [1962].

- Jean-Jacques Rousseau, fundador das ciências do homem. In: Antropologia estrutural dois. $2^{\mathrm{a}} \mathrm{ed}$. Rio de Janeiro: Tempo Brasileiro, p. 4151, 1987 [1962].

. Lévi-Strauss nos 90: Voltas ao passado. Mana: Estudos de Antropologia Social. Rio de Janeiro: PPGAS/Museu Nacional-UFRJ, v. 4(2), p. $107-117,1998$.

MAUSS, M. \& DURKHEIM, É. Algumas formas primitivas de classificação: Contribuição para o estudo das representações coletivas. In: MAUSS, M. Ensaios de Sociologia. São Paulo: Perspectiva, p. 399-455, 1999 [1903].

MAUSS, M. \& FAUCONNET, P. Sociologia. In: MAUSS, M. Ensaios de Sociologia. Trad.: Luiz João Gaio e J. Guinzburg. São Paulo: Perspectiva, p. 3-33, 1999 [1901].

MAUSS, M. Mentalidade primitiva e participação. In: CARDOSO DEOLIVEIRA, R. [org] Mauss: Antropologia. São Paulo:Ática,p. 159-163, 1979 [1923].

MERLEAU-PONTY, M. De Mauss a Claude Lévi-Strauss. In: Matrice MerleanPonty: Textos selecionados (Os Pensadores). São Paulo: Abril Cultural, p. 383-396, 1975 [1960].

NIETZSCHE, F. Além do bem e do mal: Prelidio a umna filosofia do futuro. $2^{\mathrm{a}} \mathrm{ed}$., São Paulo: Companhia das Letras, 1992 [1885].

PARSONS, T. Sociedades: Perspectivas evolutivas e comparativas.. São Paulo: Pioneira, 1969 [1966].

. O sistema das sociedades modernas. São Paulo: Pioneira, 1974 [1971].

PRADO JÚNIOR, B. Pierre Clastres. In: Alguns ensaios: Filosofia, literatura, psicanálise. São Paulo: Max Limonad, p. 251-256, 1985 [1982].

PUGLIESE, G. Um musen de grandes novidades. Sociologia, ciência è vida. São Paulo: Escala, $\mathrm{n}^{\circ}$ 9, p. 52-57, 2007.

QUIRINO, C. G. Tocqueville: Sobre a liberdade e a igualdade. In: WEFFORT, Francisco [org.]. Osclasssicos da politica(v. 2). São Paulo: Ática, p. 149-188, 1989. 
ROUSSEAU, J.-J. Discurso sobre a origem e os fundamentos da desigualdade entre os homens. In: Do contrato social e outros textos (Os Pensadores). $2^{\mathrm{a}}$ ed. São Paulo: Abril Cultural, p. 201-320, 1978 [1754/55].

SAHLINS, M. Como pensam os "nativos": Sobre o Capitão Cook, por exemplo. São Paulo: Ed. da USP, 2001 [1995].

STRATHERN, M. Entre uma melanesianista e uma feminista. Cadernos Pagu. Campinas: Núcleo de Estudos de Gênero/UNICAMP, v. 8/9, p. 7-49, 1997 [1992].

. No limite de uma certa linguagem (Entrevista com Eduardo Viveiros de Castro e Carlos Fausto). Mana: Estudos de Antropologia Social. Rio de Janeiro: PPGAS/Muscu Nacional-UFRJ, v. 5, nº 2, p. 157-175, 1999.

. O gênero da dádiva: Problemas com as mulberes e problemas com a sociedade na melanésia. Trad.: André Villalobos. Campinas: Ed. da UNICAMP, 2006 [1988].

TARDE, G. Les lois de l'imitation. Paris : Éditions Kimé, 1993[1890].

Monadologia e sociologia. In: Monadologia e sociologia - e outros ensaios. Trad.: Paulo Neves. Organização e introdução: Eduardo Viana Vargas. São Paulo: Cosac \& Naify, p. 51-131, 2007 [1895].

TOCQUEVILLE, A. A democracia na América. In: A democracia na América eo antigo regime e a revolução (Os Pensadores). $2^{\mathrm{a}}$ ed. São Paulo: Abril Cultural, p. 183-317, 1979 [1835].

VARGAS, E. V. Introdução. In: TARDE, G. Monadologia e Sociologia - e outros ensaios. São Paulo: Cosac \& Naify, p. 7-50, 2007.

VIVEIROS DE CASTRO, E. O nativo relativo. Mana: Estudos de Antropologia Social. Rio de Janciro: PPGAS/Museu Nacional-UFRJ, v. 8(1), p. 113148, 2002.

. "Perspectival anthropology and the method of controlled equivocation". Tipiti, v. 2(1), p. 3-22, 2004.

WAGNER, R. The invention of culture. $2^{\mathrm{a}} \mathrm{ed}$. Chicago: The University of Chicago Press, 1981 [1975].

Fonte on line: KECK, F. Sartre/Lévi-Strauss.http://ciepfc.rhapsodyk.net/

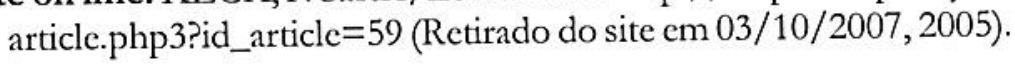

